\section{Discussion}

Particularly relevant to our study was the report of Vogl et $a l^{5}$ of the effectiveness of intermittent phototherapy on preterm infants using a short exposure time of 15 minutes in every 30,45 , or 75 minutes. Employing a different time schedule the results of our study on term infants with physiological jaundice are similar. Because all the parameters can be estimated more precisely by the polynomial model, statistical comparison between groups becomes more reliable. Neither the peak serum bilirubin concentrations nor the rates of decline after the peak has been reached were statistically different in the three groups. This result lends support to the hypothesis of two step photodegradation of bilirubin in vivo. ${ }^{6}$ The first step is the photochemical reaction at the skin site which is completed in nanoseconds. Simultaneously, unexcited bilirubin from the body pool migrates slowly into the skin loci and photo products out of the skin. This is considered to be the limiting factor in the rate of removal of unconjugated bilirubin in vivo. The time required for the second step to be completed has been estimated to be one to three hours. Therefore there may be only marginal improvement by irradiation during the second phase. The chief advantage of intermittent treatment is the reduction of total irradiance. In our study infants of group C received only $28 \%$ of the irradiance given to those in group A. Our data suggests at an irradiance of 350 $\mu \mathrm{W} / \mathrm{cm}^{2}$ a regimen of one hour of phototherapy and $\Omega$ three hours off is as effective as continuous exposure in term infants with physiological jaundice. Besides ?ำ its simplicity in application, it is also economically $\overrightarrow{\vec{D}}$ attractive for developing countries where the need is $\frac{?}{0}$ great and resources are scarce. Furthermore, this $\frac{C}{0}$ regimen is less disruptive to the establishment of $\frac{\bar{\sigma}}{\overline{0}}$ infant maternal bonding and breast feeding because $\vec{\nabla}$ the infants are not confined to the incubators during 2 the whole course of treatment.

\section{Réferènces}

1 Mauer HM, Shumway CN, Draper DA, Hassaini AA. Con- $\vec{\omega}$ trolled trial comparing agar, intermittent phototherapy, and continuous phototherapy for reducing neonatal hyperbilirubinaemia. J Pediatr 1973;82:73-6.

2 Zachmann RD. Alternate phototherapy in neonatal hyperbilirubinaemia. Biol Neonate 1974;25:283-8.

3 Rubaltelli FF, Zanardo V, Granati B. Effect of various phototherapy regimes on bilirubin decrement. Pediatrics 1978;61:838-41.

+ Ostle B. Statistics in research. 2nd ed. Ames, Iowa: The lowa 음 State University Press, 1963:161-92.

${ }^{5}$ Vogl TP, Hegyi T, Hiat IM, Polin RA, Indyk L. Intermittent $C$ phototherapy in the treatment of jaundice in the premature $\mathbb{D}$ infant. $J$ Pediatr 1978;92:627-30.

6 McDonagh AF. Mechanism of action of phototherapy. In: Levine RL, Maisels MJ, eds. Hyperbilirubinaemia in the newborn. Report of the eighty-fifth Ross Conference on $\frac{\mathbb{D}}{-}$ Pediatric Research. Columbus, Ohio: Ross Laboratory, $\vec{c}$ 1983:47-53.

Correspondence to Dr S P Lau, Paediatric Department, Quecen Mary Hospital, University of Hong Kong, Hong Kong.

Received 27 March 1984

\title{
Mebendazole in the treatment of hydatid cysts
}

\author{
T KARPATHIOS, V SYRIOPOULOU, P NICOLAIDOU, AND J MESSARITAKIS
}

1st Paediatric Clinic of Athens University School of Medicine, Greece

SUMMARY We report two children with ruptured, multiple hydatid cysts treated with mebendazole. Long term follow up has confirmed the success of this treatment.

Surgical intervention in ruptured or multiple hydatid cysts may meet with failure; treatment with mebendazole is justified in these cases but almost all published reports have been in adults. ${ }^{1-3}$ We report two children with multiple, ruptured hydatid cysts who were successfully treated with mebendazole.

\section{Case reports}

Case 1. A 13 year old boy was admitted to hospital in August 1977 because of paroxysmal cough which을. resulted in vomiting. Chest radiography showed $\mathrm{a}_{\mathrm{N}}$

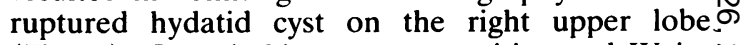
(Figure). Casoni skin test was positive and Wein- N berg (complement fixation) test and echinococcal $\mathbb{\omega}_{\mathrm{W}}$ antibodies determined by immunoelectrophoresis were negative. Surgery was advised but his parents refused permission.

In June 1980 he was readmitted to hospital having $\stackrel{\oplus}{?}$ suffered two episodes of haemoptysis during the 7 


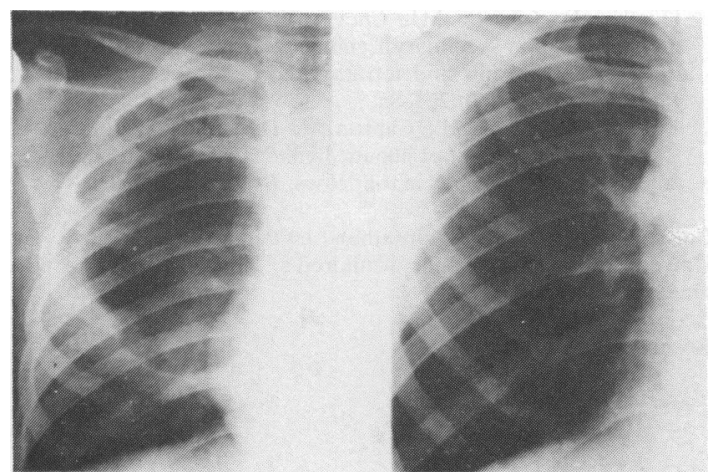

Figure Chest radiograph (right hemithorax) of case 1 . Left before treatment and right after treatment with mebendazole.

previous 48 hours. Between this hospital admission and the previous one he had repeatedly experienced symptoms simulating chest infection and had been treated with antibiotics. On admission diminished breath sounds were detected in the right lung. Chest radiograph showed collapse of the right lung and on bronchoscopy remnants of hydatid cyst were found and excised. Casoni skin test was positive and Weinberg and echinococcal antibodies determined by immunoelectrophoresis were negative. The results of other laboratory investigations were: haemoglobin $11 \mathrm{~g} / \mathrm{dl}$, leukocyte count $10 \cdot 2 \times 10^{9} / 1$ (56\% neutrophils, 38\% lymphocytes, and $6 \%$ eosinophils), alkaline phosphatase $170 \mathrm{U} / 1$, serum glutamic oxaloacetic transaminase $72 \mathrm{U} / 1$, and serum glutamic pyruvic transaminase $62 \mathrm{U} / \mathrm{l}$.

Penicillin was given for 10 days and mebendazole for 10 weeks - in a dose of $50 \mathrm{mg} / \mathrm{kg} / \mathrm{day}$ for two weeks and $100 \mathrm{mg} / \mathrm{kg} /$ day for a further eight weeks. At the end of the treatment a chest radiograph showed definite improvement. The patient has remained asymptomatic for three years and his latest radiograph (done at this time) was absolutely normal. (Figure).

Case 2. An 8 year old girl was admitted to hospital in August 1981 because of recurrent acute abdominal pain over a period of five days. Clinical examination showed diminished breath sounds in both lungs and a soft, smooth, and non-tender liver palpable $3 \mathrm{~cm}$ below costal margin. Chest radiograph showed three cysts on the right and one cyst on the left lung. Abdominal computed tomography showed a large cyst approximately $5 \times 6 \mathrm{~cm}$ in size on the liver. Casoni skin test was positive, Weinberg test was negative, and ELISA test was positive (more than 1:12 000). Other investigations included haemoglo- bin concentration $12.4 \mathrm{~g} / \mathrm{dl}$; leukocyte count $13.7 \times 10^{9} / 1$ (64\% neutrophils, $31 \%$ lymphocytes, and $5 \%$ eosinophils); alkaline phosphatase $115 \mathrm{U} / \mathrm{l}$; serum glutamic oxaloacetic transaminase $32 \mathrm{U} / \mathrm{l}$; and serum glutamic pyruvic transaminase $20 \mathrm{U} / \mathrm{l}$. Because there were several echinococcal cysts we started treatment with oral mebendazole in a dose of $100 \mathrm{mg} / \mathrm{kg} /$ day for 12 weeks. Ten days after the start of treatment she developed a fever of $38.5^{\circ} \mathrm{C}$ which stopped spontaneously within two days. On the sixth week of treatment her serum glutamic oxaloacetic and pyruvic transaminase concentrations were abnormally high (860 and $570 \mathrm{U} / 1$ respectively) but these returned to normal (43 and $24 \mathrm{U} / \mathrm{l}$ respectively) a fortnight later. Twenty days after the start of treatment the patient suffered vomiting after bouts of paroxysmal coughing. Chest radiograph showed rupture of the three cysts in the right lung. Three months later she again vomited and a second chest radiograph showed rupture of the cyst in the left lung. One year later computed tomography showed a solid mass on the base of the left lung and another on the apex of the right lung. A computed tomogram of the liver showed a small calcified cyst in the middle. The latest chest radiograph two years after the first showed only the two small residual lesions.

\section{Discussion}

Mebendazole must have been responsible for the cessation of symptoms and the resolution of the radiological findings in the first patient. Good results with mebendazole in ruptured hydatid cysts have also been reported in an adult who finally had his cyst removed surgically because of superimposed infection. ' In our patient there was no need for surgical intervention during or after treatment: no complications were noted during the three years of follow up.

In the second patient three out of four cysts had ruptured a few days after beginning treatment, probably because mebendazole had rendered their walls friable. ${ }^{4}$ The residual solid masses must have comprised fibrous tissue as has been postulated by others. ${ }^{5}$ It is interesting to note that all pulmonary cysts in this patient showed variable response to the treatment, although they were all of the same size.

Serious side effects from mebendazole were not observed. Only a transient increase in concentrations of transaminases was found; these returned to normal within two weeks despite the continuation of treatment. In conclusion, the results obtained in our two patients justify treatment with mebendazole, at least in patients with ruptured or multiple hydatid cysts. 
We thank Drs F Psychou and F Papadellis for their help in the management of our patients.

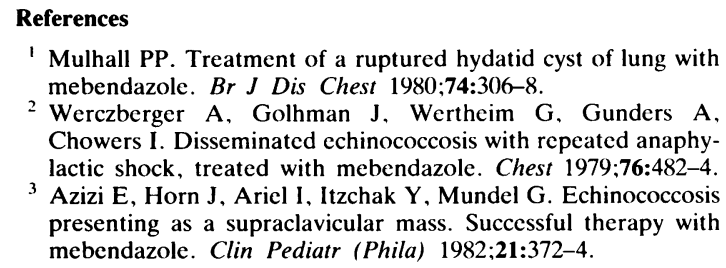

1 Mulhall PP. Treatment of a ruptured hydatid cyst of lung with mebendazole. Br J Dis Chest 1980;74:306-8.

2 Werczberger A, Golhman J, Wertheim G, Gunders A, Chowers I. Disseminated echinococcosis with repeated anaphylactic shock, treated with mebendazole. Chest 1979;76:482-4.

${ }^{3}$ Azizi E, Horn J, Ariel I, Itzchak Y, Mundel G. Echinococcosis presenting as a supraclavicular mass. Successful therapy with mebendazole. Clin Pediatr (Phila) 1982:21:372-4.

${ }^{4}$ Heath DD, Christic MJ. Chevis RAF. The lethal effect of $\frac{\Omega}{\partial}$ mebendazole on secondary Echinococcus granulosus, cysticerci of Taenia pisiformis and tetrathyridia of Mesocestoides corti. Parasitology 1975;70:273-85.

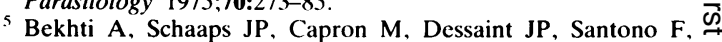
Capron A. Treatment of hepatic hydatic disease with mebendazole: preliminary results in four cases. Br Med J 1977;ii:1047-51.

Correspondence to Dr T Karpathios, 1st Pediatric Clinic of Athens University, 'Aghia Sophia' Children's Hospital, Athens 608, 凤 Greece.

Received 29 March 1984

\title{
Extrahepatic biliary obstruction due to stone
}

\author{
P J SHAW, L SPITZ, AND J G WATSON \\ Department of Paediatrics, Royal Free Hospital and Department of Paediatric Surgery, Institute of Child \\ Health, London
}

SUMMARY Jaundice developing after the neonatal period requires prompt investigation. Surgical causes of cholestatic jaundice, apart from extrahepatic biliary atresia and choledochal cyst, are rare. We describe a case of bile duct dilatation associated with an impacted calculus at the ampulla of Vater in a haemophiliac. The ultrasound finding of a dilated duct was an indication to proceed to surgery.

Full investigation of cholestatic jaundice in infancy is important to diagnose those lesions which may be correctable surgically. The differential diagnosis of extrahepatic biliary obstruction includes extrahepatic biliary atresia, bile duct perforation, stenosis and cyst, and biliary 'sludging'. We present a case of common bile duct stone which, although extremely rare and readily treatable, was difficult to diagnose.

\section{Case report}

A boy was born at term to an obligate carrier of haemophilia A. At birth his factor VIII value was $2.5 \%$. He was breast fed and developed mild unconjugated jaundice (on day 3 his total bilirubin concentration was $158 \mu \mathrm{mol} / \mathrm{l}$; conjugated bilirubin $11 \mu \mathrm{mol} / \mathrm{l}$ ) which had cleared by day 7 . At 18 weeks of age he became intermittently fretful with occasional screaming attacks. Physical examination was normal. Biochemical evidence of haematoma was excluded by finding normal haptoglobin and methaemalbumin concentrations. Total bilirubin concentration was $50 \mu \mathrm{mol} / \mathrm{l}$, aspartate transaminase $308 \mathrm{U} / \mathrm{l}$ (normal 5 to $40 \mathrm{U} / 1$ ), and alkaline phosphatase $274 \mathrm{U} / \mathrm{l}$ (normal 35 to $130 \mathrm{U} / \mathrm{l})$. Serological tests for toxoplasma, toxocara, rubella, cytomegalovirus, herpes simplex, syphilis, varicella zoster, and hepa titis $\mathrm{A}$ and $\mathrm{B}$ were negative. Abdominal ultrasoun was normal. After one week his bilirubin concentro tion had fallen to $11 \mu \mathrm{mol} / \mathrm{l}$, his aspartate transam nase concentration was $145 \mathrm{U} / \mathrm{l}$, and he was much more content.

Two weeks later he again became very fretful, and developed overt jaundice with pale, foul smelling stools and pruritus. A liver edge was now palpable $4 \mathrm{~cm}$ below the costal margin. His bilirubin concentration at this time was $60 \mu \mathrm{mol} / \mathrm{l}$ and his conjugated bilirubin was $48 \mu \mathrm{mol} / 1$. Routine haematology and biochemical determinations were normal, as were the immunoglobulins, $\alpha_{1}$ antitrypsin, plasma amino acids, thyroxine, sweat sodium and chloride, prothrombin time, and amylase. Urine was negative for reducing substances on three occasions. The liver function tests became increasingly abnormal, with aspartate transaminase $298 \mathrm{U} / \mathrm{l}$, alkaline phosphatase $910 \mathrm{U} / \mathrm{l}$, and total bilirubin concentration $138 \mu \mathrm{mol} / \mathrm{l}$. His prothrombin ratio was 4 . Other abnormal results included serum cholesterol $20 \cdot 9 \mathrm{~N}$ $\mathrm{mmol} / \mathrm{l}$ (normal 3 to 6.5 ) and triglycerides $2.9 \mathrm{~mol} / \mathrm{l}$. (normal 0.2 to 1.5 ). Real time ultrasonography on $\mathrm{N}$ this occasion showed dilated intra- and extrahepatic $\underset{\omega}{\mathrm{N}}$ bile ducts and a common bile duct of $11 \mathrm{~mm}$ 으 maximum diameter. The gall bladder was distended 0 but contained no sludge or calculi. The grossly $\underset{\mathbb{D}}{\overparen{D}}$ dilated system made a diagnosis of choledochal cyst $\stackrel{\infty}{\rightarrow}$ likely and he was transferred for surgery. 寞 